\title{
The NCAR-FAA Snow Machine: An Artificial Snow-Generation System
}

\author{
SCOTT D. LANDOlt, Roy M. Rasmussen, AND Alan J. Hills \\ National Center for Atmospheric Research, Boulder, Colorado \\ WARREN UNDERWOOD \\ Federal Aviation Administration, Atlantic City, New Jersey \\ Charles A. KNight AND Albert JaChCiK \\ National Center for Atmospheric Research, Boulder, Colorado \\ ANDREW SCHWARTZ \\ National Center for Atmospheric Research, Boulder, Colorado, and University of Queensland, \\ Brisbane, Queensland, Australia
}

(Manuscript received 17 January 2018, in final form 7 September 2018)

\begin{abstract}
The National Center for Atmospheric Research (NCAR) developed an artificial snow-generation system designed to operate in a laboratory cold chamber for testing aircraft anti-icing fluids under controlled conditions. Flakes of ice are produced by shaving an ice cylinder with a rotating carbide bit; the resulting artificial snow is dispersed by turbulent airflows and falls approximately $2.5 \mathrm{~m}$ to the bottom of the device. The resulting fine ice shavings mimic snow in size, distribution, fall velocity, density, and liquid water equivalent (LWE) snowfall rate. The LWE snowfall rate can be controlled using either a mass balance or a precipitation gauge, which measures the snowfall accumulation over time, from which the computer derives the LWE rate. LWE snowfall rates are calculated every $6 \mathrm{~s}$, and the rate the ice cylinder is fed into the carbide bit is continually adjusted to ensure that the LWE snowfall rate matches a user-selected value. The system has been used to generate LWE snowfall rates ranging from 0 to $10 \mathrm{~mm} \mathrm{~h}^{-1}$ at temperatures from -2 to $-30^{\circ} \mathrm{C}$ and densities of approximately $0.1-0.5 \mathrm{~g} \mathrm{~cm}^{-3}$. Comparisons of the snow-machine fluid tests with the outdoor fluid tests have shown that the snow machine can mimic natural outdoor rates under a broad range of conditions.
\end{abstract}

\section{Introduction}

An artificial snow-generation "snow machine" system was developed for use in a laboratory environment in which a variety of deicing and anti-icing fluids developed around the world could be tested and characterized before being certified for use on aircraft. Aircraft deicing fluids are used to remove any contamination on the aircraft surface that could hinder smooth airflow across the wing surfaces. Aircraft anti-icing fluids are applied after the deicing fluids to prevent the accumulation of snow and ice on the aircraft while the aircraft prepares for takeoff. For the purposes of this paper, the term icing refers to snow buildup and adhesion to an

Corresponding author: Scott Landolt, landolt@ucar.edu aircraft surface while the aircraft is still on the ground, and it is not meant to be confused with in-flight icing, which occurs when an aircraft encounters supercooled liquid water conditions during flight.

The development of the snow machine also allowed the opportunity to research the mechanisms that can cause deicing and anti-icing fluids to fail when protecting against snow and ice accumulation under controlled conditions. The primary focus was on testing anti-icing fluids, because these are the fluids that protect the aircraft prior to takeoff. These fluids are generally composed of propylene or ethylene glycol; thickeners are added to prevent them from rapidly running off the aircraft surfaces and thus provide more time for snow falling onto the fluid to dissolve into it rather than adhering to the aircraft surface. 


\section{Background}

\section{a. Anti-icing fluid testing}

Prior studies (Bernadin et al. 1997; Rasmussen et al. 1999a,b, 2003, 2006, 2012) revealed that the principal factor causing aircraft de/anti-icing fluids to stop absorbing snow on a wing is the amount of water that is dissolved into the fluid. This is best characterized by the liquid water equivalent (LWE) snowfall rate. It is important for airline personnel to know the expected endurance time (the period over which the anti-icing fluid provides protection to aircraft surfaces) of an anti-icing fluid for natural snow conditions for a given ambient temperature and LWE snowfall rate. Traditionally, establishing endurance times for anti-icing fluids in snowfall conditions involved outdoor testing in natural conditions. An aluminum panel, sloped at $10^{\circ}$ from horizontal to simulate an aircraft wing, is typically attached at the top and bottom to a freestanding support structure with a fluid catchment container placed on the ground underneath (Fig. 1). The standard outdoor fluid testing procedure is to pour a specified amount of antiicing fluid (typically $0.5-1 \mathrm{~L}$ ) onto the panel, face the apparatus into the prevailing wind, and then wait for the fluid to stop absorbing the snow until snow accumulates on top of the fluid, covering a minimum of $30 \%$ of the plate area. This establishes the endurance time for that particular test run. Because the viscosity of the antiicing fluids changes with different temperatures and LWE snowfall rates, these tests must be done under varying combinations of those conditions.

Running these tests outdoors in natural snow conditions can be costly and time consuming though, especially if target conditions cannot be achieved, which may require testing over a second winter season. In addition to the cost and time, outdoor atmospheric conditions such as wind speed and direction, air temperature, and LWE snowfall rate are highly variable and can change rapidly during the tests, adding additional uncertainty to the derived endurance times. Thus, in practice, it is often difficult to compare tests from one snow event to another, as the exact conditions are seldom duplicated. To minimize variability between outdoor tests, multiple panels can be used simultaneously while testing a new fluid concurrently with a reference fluid, but this requires additional personnel and resources. Nevertheless, significant variability in weather conditions remains when conducting outdoor anti-icing fluid testing.

In contrast to outdoor snow testing, indoor laboratory snow testing in a cold chamber provides an environment where temperature and LWE snowfall rates can be controlled, and wind effects minimized, allowing for year-round testing. Laboratory testing also allows for

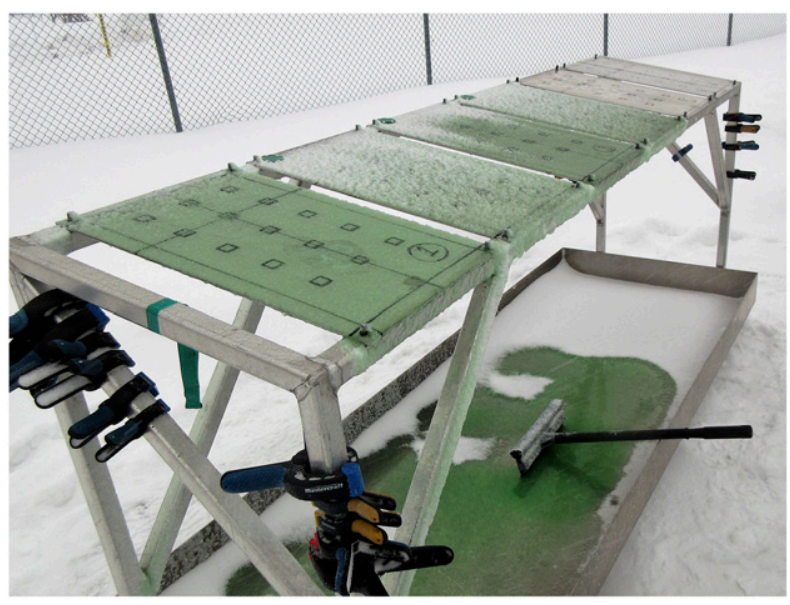

FIG. 1. Example outdoor anti-icing fluid testing assembly.

repeat testing under similar conditions to establish reliability and error limits. This also provides opportunities to establish functional relationships between variables by isolating variables for specific testing designs. Before the development of the snow machine, the main obstacle preventing the testing of anti-icing fluids in laboratories was the lack of an appropriate method to generate realistic snowfall in terms of duration, rate, density, and spatial uniformity.

\section{b. Artificial snow generation}

Researchers at the Université du Québec à Chicoutimi developed an indoor fluid testing system in the 1990s (Bernadin et al. 1997). The first version used natural snow, sifted to an approximate range of "snow" sizes, and then distributed under computer control onto an artificial wing surface (AWS), described in more detail in section 4 . A more recent system freezes $300-\mu \mathrm{m}$ water drops in a cold chamber and scrapes the drops into a hopper, which then deposits them onto an AWS from a height of $0.5 \mathrm{~m}$. The hopper position is computer controlled, allowing for a uniform snow distribution across the AWS. This system has the advantages expected of testing done in indoor cold chambers (i.e., repeatability, temperature control, rate control, and lack of wind). The disadvantage of the system is that the snow particles generated by clumping the $300-\mu \mathrm{m}$ water drops together are unrealistically large in size ( $25 \mathrm{~mm}$ in diameter with a bulk density of approximately $0.1 \mathrm{~g} \mathrm{ml}^{-1}$ ). Furthermore, the snow particles do not fall at their terminal velocity, and thus their effect on the AWS (and fluid) is unrealistic.

We also note that the ski industry has a history of methods for producing artificial snow on ski slopes when insufficient snow exists to support skiing conditions. The most-used artificial snow-generation technique sprays 
cold water through an air-injected nozzle into subfreezing ambient conditions. Similar to the machine developed by the Université du Québec à Chicoutimi, this method produces only small frozen-liquid water droplets approximately $100-500 \mu \mathrm{m}$ in size, which do not represent snow conditions that may be experienced by airplanes awaiting takeoff. Thus, there is a motivation to develop new snowfall-generation techniques.

\section{NCAR snow machine}

\section{a. Description}

The snow machine (Fig. 2) is $2.8 \mathrm{~m}$ tall and has a footprint of $0.9 \mathrm{~m}$ wide $\times 0.7 \mathrm{~m}$ deep. The machine's width gradually tapers with height, resulting in a width of $0.65 \mathrm{~m}$ at its top. Aluminum struts provide a support framework upon which clear polycarbonate sheets are mounted. The polycarbonate sheets contain the snow within the machine as it falls and prevent room air currents from perturbing the controlled airflow and snowfall patterns within the machine. The height of the machine allows the snow to reach terminal velocity before reaching the bottom. The machine is bolted together near its midpoint for simple breakdown and transport. The front and rear surfaces use hinged polycarbonate sheets as doors, which close with magnetic latches, allowing access to both the upper and lower portions of the machine. Located near the top of the machine, at a height of $2.5 \mathrm{~m}$, is the ice-shaving system. Placed at the base of the snow machine is an electronic mass balance used for deriving the real-time LWE snowfall rates. The primary electronics and a desktop PC, which control the machine and acquire all data, reside in a heated portion of the laboratory. An overview of the snow-machine components follows.

\section{b. Translator/ice shaver assembly}

Artificial snow is produced by shaving a cylinder of ice using a custom-designed Forstner-style tungsten carbide bit turned by a drill press. The drill press is bolted to the upper part of the snow machine, parallel to the axis of the stepper motor/translator assembly (Fig. 3). The fivespeed drill press is normally operated at $2340 \mathrm{rpm}$, which provides a range of flake sizes ( 0.05 - to $\sim 1$-cm diameter) consistent with observed natural snowflakes (Fig. 4). Increasing the rotational bit speed decreases the flake size. The snow generated by the system is not intended to mimic actual snowflakes found in nature (dendrites, plates, etc.), but rather the size distribution and density that is typical of natural snow. The ice cylinder is moved via a linear translator that is lead-screw driven by a stepper motor (Fig. 3, labels 1 and 2). The ice cylinder is

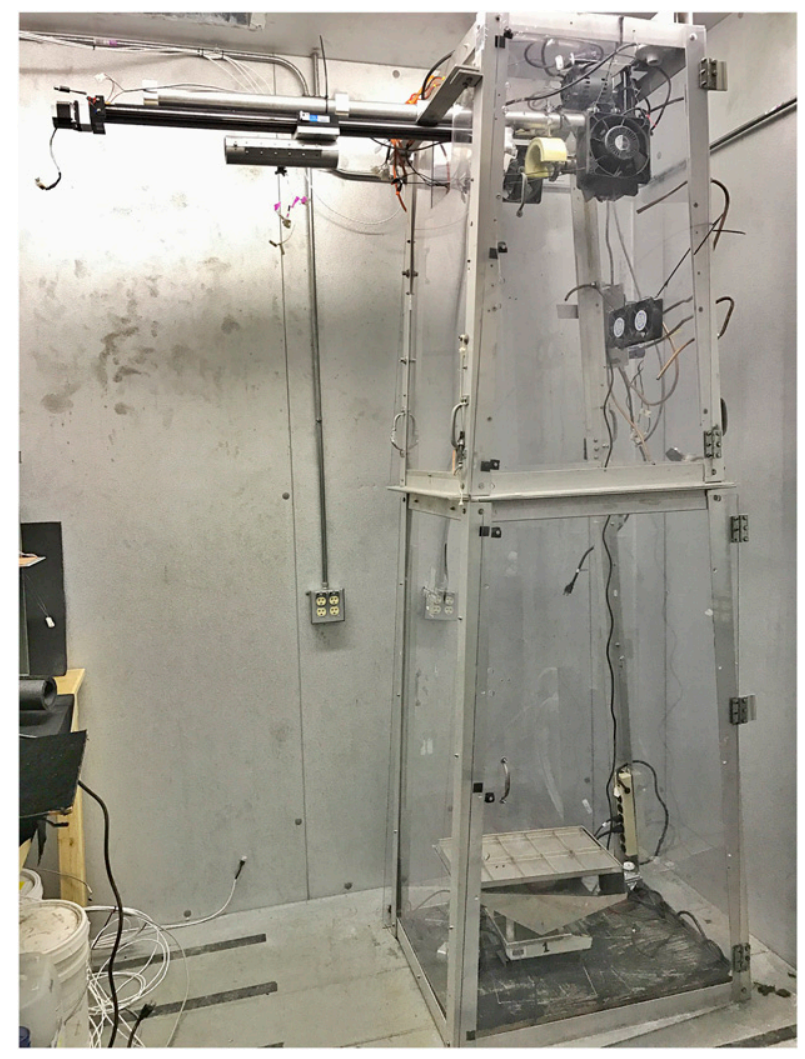

FIG. 2. Snow machine in the cold chamber.

supported at the translator carriage with a custom mount and clamp assembly (Fig. 3, label 3). A bolt at the rear of the translator carriage transfers the forward movement of the translator carriage to the ice cylinder. A nonmoving spring-loaded guide with three wheels (Fig. 3, label 4) located near the carbide bit supports the ice cylinder during its forward movement, preventing vibration and potential fracturing/breaking of the ice cylinder. Contact switches placed at both ends of the translator serve to interrupt the stepper-drive signal so that ice cylinder translation automatically stops at the end positions of the translator movement. From a total length of $135 \mathrm{~cm}$, only $90 \mathrm{~cm}$ of the ice cylinder are used for artificial snow generation; the remaining length is held in the clamp assembly.

As with natural snow, the snow generated by the machine can sometimes adhere to vertical surfaces. To minimize snow buildup at the top of the machine and on the sidewalls, a small half-circular-shaped shroud with an inner foam lining (Fig. 3, label 6) was designed to be slightly larger than the carbide bit (Fig. 3, label 7). The shroud is suspended near the carbide bit and attached to an arm mounted from the ceiling of the machine. The carbide bit itself was designed to include metal whiskers that are attached to, and rotate with, 

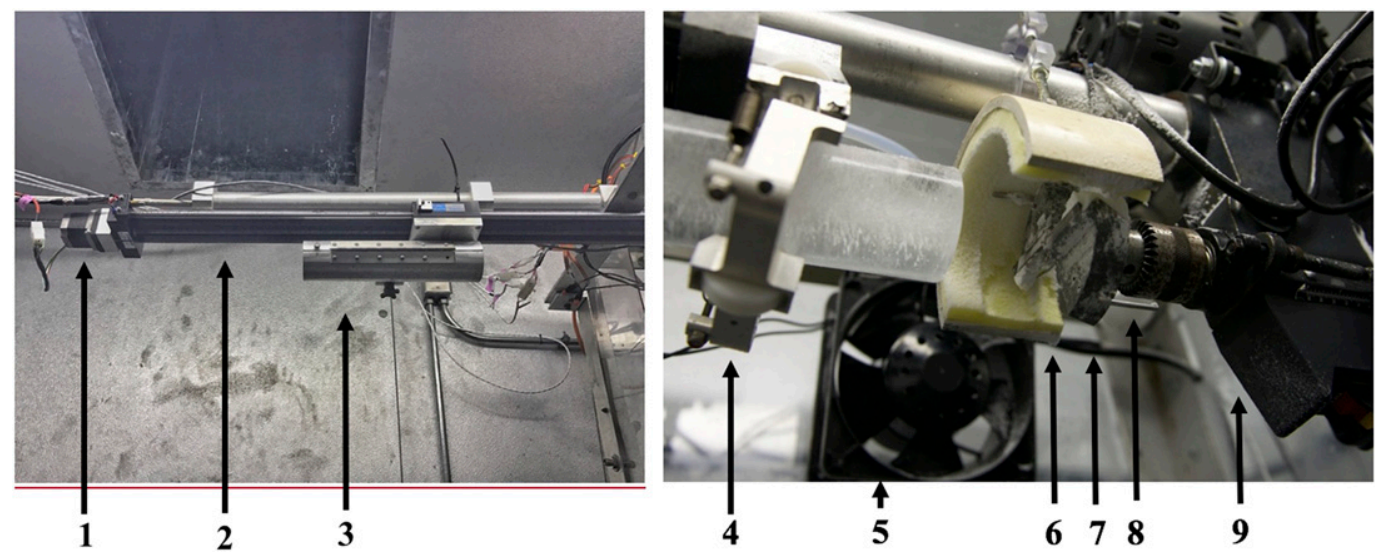

FIG. 3. Stepper motor (item 1) attached to the translator assembly (item 2). The hinged mount (item 3) supports the ice cylinder as it is fed into the machine. The spring-loaded guide (item 4) helps prevent the ice cylinder from vibrating and breaking as it is being shaved. Fans (item 5) help redistribute snow in the machine. A shroud (item 6) over the custom-designed drill bit (item 7) with attached whiskers (item 8) prevents snow buildup at the top of the machine. The horizontally mounted drill press can be seen at the right (item 9).

the bit to remove snow buildup on the shroud so that the snow can fall vertically only below the bit (Fig. 3, label 8). Foam was used to line the shroud to provide a flexible surface for the whiskers to brush to easily remove the snow buildup. This helps prevent snow from falling in clumps off the ceiling and sidewalls and onto the AWS testing surfaces at the bottom of the machine. Fans (Fig. 3, label 5) are also used in the machine to help randomize the snowfall distribution pattern at the bottom of the machine.

\section{c. Ice cylinder generation}

The snow generated by the machine is produced from ice cylinders that are $6 \mathrm{~cm}$ in diameter and $135 \mathrm{~cm}$ in length. These ice cylinders are created by pouring distilled water into thick-walled aluminum tubes sealed at

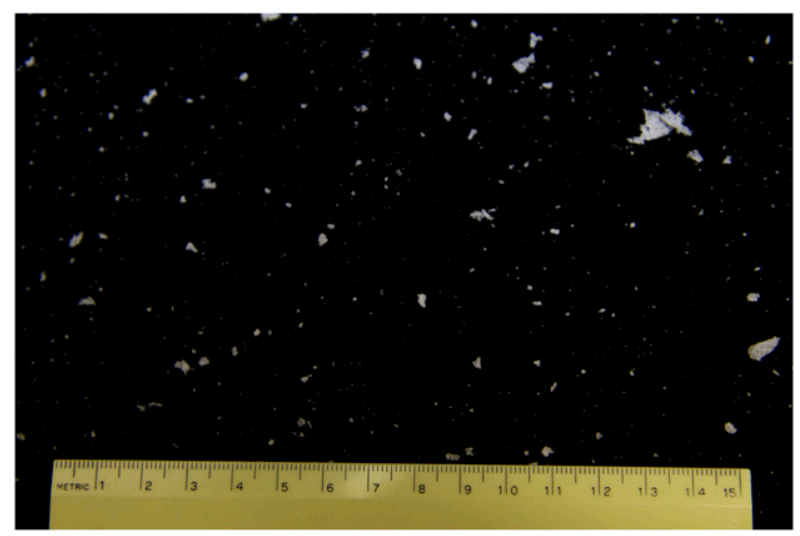

FIG. 4. Example of "snowflake" sizes generated by the snow machine. A ruler marked in centimeters is shown at the bottom. one end with an aluminum plate that allows them to stand vertically (Fig. 5, left panel). Distilled water is used to prevent minerals dissolved in the water from potentially interacting or reacting with the anti-icing fluid, which could affect the resulting endurance times of the fluids. Once filled, the aluminum tubes are placed in the cold chamber, allowing the water to freeze. To prevent the ice from freezing from the top down, which can easily break the aluminum plate off the bottom, thick insulation is used on the upper parts of the tube, tapering to bare aluminum at the bottom (Fig. 5, center panel). This modification results in ice cylinders that freeze initially at the bottom and then slowly upward. Once the ice cylinders are frozen, they are removed from the aluminum tubes by allowing them to thaw slightly in a warm room until they can be slid out of the tube (Fig. 5, right panel).

\section{d. LWE rate measurements}

To test aircraft anti-icing fluids in the snow machine, a custom-designed fluid catchment assembly was built that consisted of the AWS inset into a fluid containment unit placed on top of a high-capacity electronic mass balance that continuously measures the mass of the snow accumulation on the AWS while the machine is in use (Fig. 6, left panel). The fluid catchment assembly supports the AWS and provides a frame of $0.8 \mathrm{~cm}$ on the top and sides and $2.5 \mathrm{~cm}$ on the lower edge, ensuring that all fluid added during an experiment is completely contained. This is necessary because LWE snowfall rates are calculated using the change in mass of the entire AWS/catchment assembly during the experiment. By confining the fluid to the plate and fluid container assembly, any measured change in mass is solely 

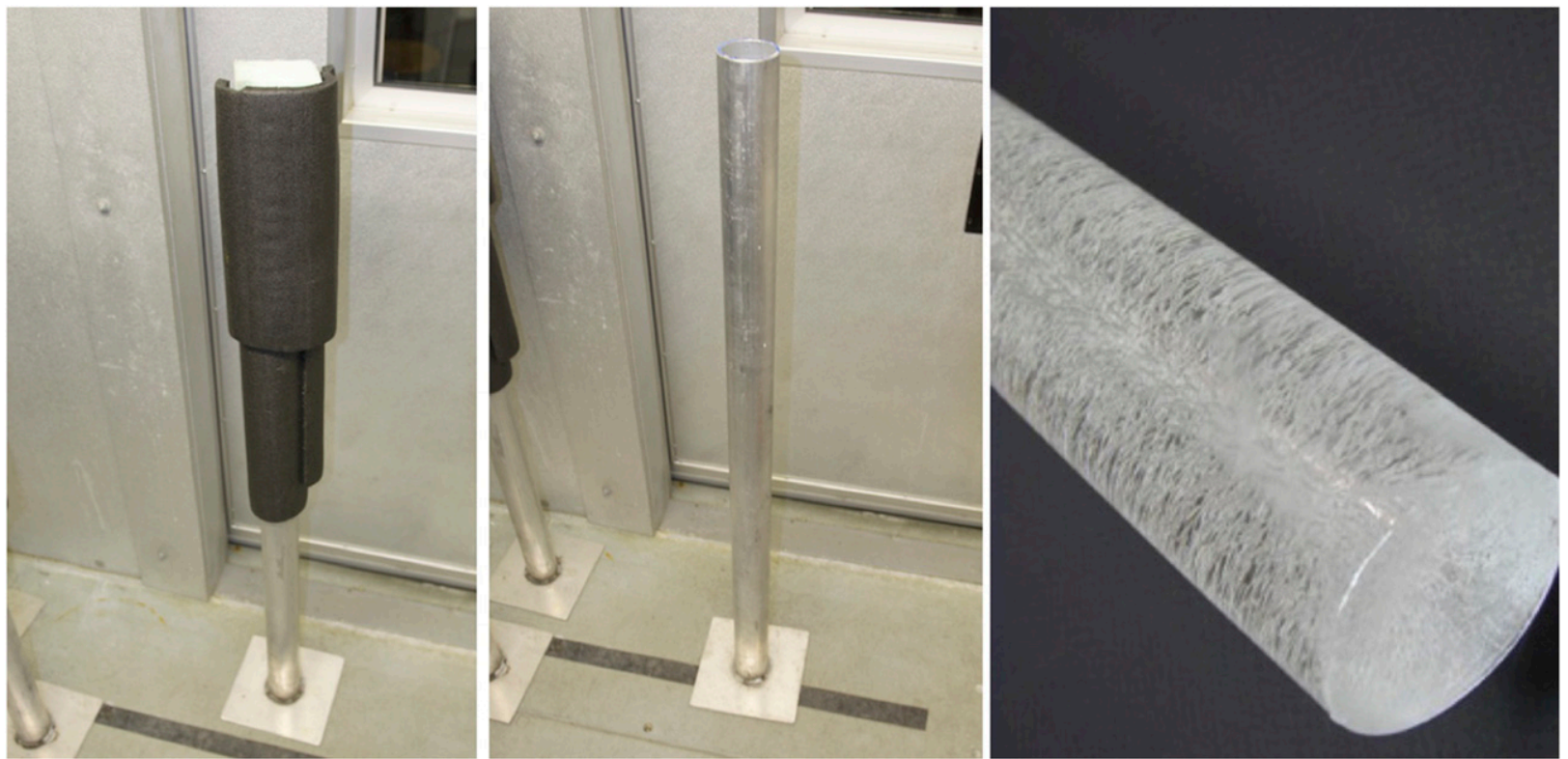

FIG. 5. (left) Ice cylinder form showing the gradient pipe insulation used to freeze the cylinder from the bottom to the top and (center) a standard ice cylinder mold. (right) A close-up view of the ice cylinder after removal from the aluminum mold.

attributed to the addition of snow. The mass of the fluid catchment assembly is read by the data acquisition system once per second with a mean value calculated every $6 \mathrm{~s}$. LWE snowfall rates are then derived from these mass measurements, which the software monitors. If the derived rate is higher (lower) than the user-defined target rate, the software will decrease (increase) the translator speed until the desired rate is achieved. The software can also be modified to accept archived LWE snowfall-rate measurements from precipitation gauges, and/or other instruments, collected during outdoor snowfall events, allowing the snow machine to replicate natural, nonconstant rates.

\section{e. Producing a uniform distribution of the artificial snow}

When testing aircraft anti-icing fluids, it is important to ensure that the snowfall pattern across the testing area has a uniform distribution similar to what would be experienced in the natural environment. To help
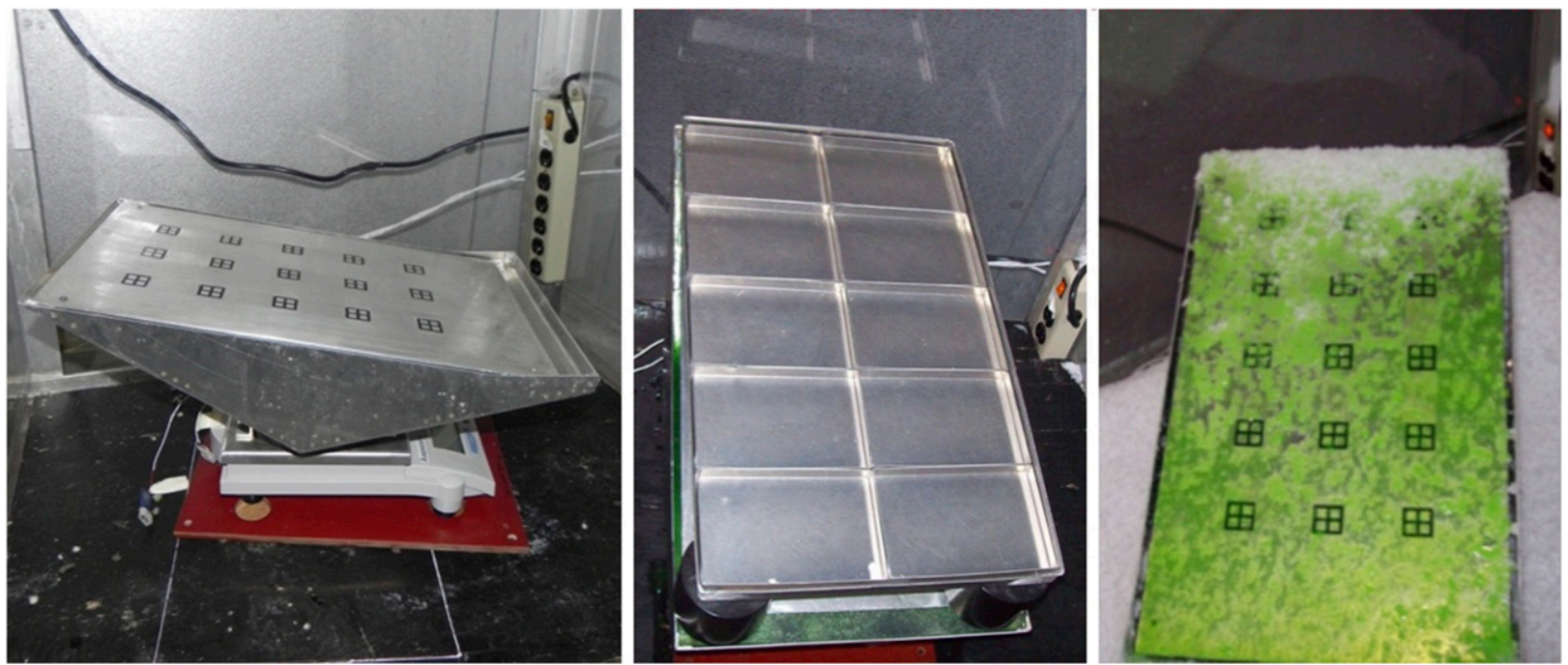

FIG. 6. (left) AWS tray catchment assembly and mass balance. (center) Trays placed on the AWS used for determining spatial uniformity of the snow pattern. (right) Example fluid failure. 
distribute the snow more evenly, fans were placed and aimed throughout the machine to produce a uniform distribution across the test surface to within $\pm 20 \%$. This requirement was established by the Society of Automotive Engineers (SAE 2008). The distribution was measured using $10 \mathrm{~cm} \times 15 \mathrm{~cm}$ subplate measurements of snow after running the machine for $10 \mathrm{~min}$, then weighing each pan and calculating the percent difference between the pans with the most and least snow (Fig. 6, center panel). Adjusting the positions and orientation of the fans changed the distribution; these were changed until the desired distribution results were achieved. Because of the isolated and controlled design of the machine, the snow distribution pattern is highly reproducible once the $\pm 20 \%$ distribution is achieved.

\section{f. Computer interface}

The primary interface between the user and the snow machine is a customized graphical user interface (GUI) using National Instrument's LabVIEW software package. The snow rate can be set to any constant value between 0 and $80.0 \mathrm{~g} \mathrm{dm}^{-2} \mathrm{~h}^{-1}\left(8 \mathrm{~mm} \mathrm{~h}^{-1} \mathrm{LWE}\right)$; or, the rate may be adjusted to simulate a previously recorded outdoor snow event by inputting a file with the timevarying mass values from the event. The units of grams per decimeter squared per hour $\left(\mathrm{g} \mathrm{dm}^{-2} \mathrm{~h}^{-1}\right)$ are the preferred units used by the international aviation ground deicing community. For reference, an LWE rate of $10 \mathrm{~g} \mathrm{dm}^{-2} \mathrm{~h}^{-1}$ is equivalent to an LWE rate of $1 \mathrm{~mm} \mathrm{~h}^{-1}$. Data are output from the software once every $6 \mathrm{~s}$ and include time, measured LWE snowfall rate and snow mass, high-resolution temperature measurements (which will be described in more detail in section 4), and any comments entered by the user during the experiment.

\section{Aircraft anti-icing fluid testing}

\section{a. Fluid testing techniques}

One of the goals of the snow machine is to produce results comparable to outdoor testing of anti-icing fluids. The purpose of these anti-icing fluids is to prevent the buildup of snow and ice on critical aircraft surfaces (wings, winglets, etc.) Aircraft deicing is usually a twostep process. Deicing the aircraft using a glycol-based type I fluid is the first step. Type I fluids are heated to between $60^{\circ}$ and $80^{\circ} \mathrm{C}$, and are sprayed at high velocity onto the aircraft, and melt and/or forcibly remove any ice/snow contamination. Type I fluids are intended to quickly run off the aircraft surfaces, providing only a short time to protect the aircraft before anti-icing fluids can be applied.
The second step is to apply a thickened, nonheated, glycol-based anti-icing fluid (referred to as type II, III, or IV) to the aircraft that sticks to the aircraft surface and absorbs falling precipitation. These fluids are nonNewtonian; that is, shear generated at their surface from high winds $\left(>35 \mathrm{~m} \mathrm{~s}^{-1}\right.$ such as when the aircraft is moving down the runway for takeoff) causes a change in viscosity and enables the fluid to flow off the aircraft. This is necessary to minimize the impact of the fluid on the aerodynamics of the airfoil. The length of time the anti-icing fluids protect the aircraft depends primarily on the characteristics of the fluid, the ambient air temperature, and LWE precipitation rate. This time is referred to as the fluid endurance time, and standards for these endurance times are determined through tests as described below.

The techniques outlined by Beisswenger et al. (2002) and SAE (2008), intended to replicate closely the operational application process, were outlined briefly above but will be described in more detail here. The technique used in snow-machine tests uses an AWS, similar to the outdoor tests, and is a single aluminum plate, sloped at a $10^{\circ}$ from horizontal to simulate an aircraft wing. The AWS is fabricated to Federal Aviation Administration (FAA) and Society of Automotive Engineers (SAE) specifications for aircraft anti-icing fluid testing and is a $30 \mathrm{~cm} \times 50 \mathrm{~cm} \times 0.3 \mathrm{~cm}$ smooth aluminum plate that is inset into the fluid catchment assembly described in section $3 d$ (SAE 2008). Anti-icing fluid is poured onto the AWS at the top of the plate and allowed to flow down and cover the plate. The snow machine is then started and snow falls onto the fluid until it is visually determined that the fluid has failed. The failure is similar in manner to the outdoor tests (described in section $2 \mathrm{a}$ ), where $30 \%$ of the AWS surface has snow/slush buildup that persists on the surface for at least $30 \mathrm{~s}$ without being absorbed by the fluid (Fig. 6, right panel). The time elapsed to reach failure is then recorded as the endurance time for that air temperature and LWE snowfall rate. Multiple tests under these same conditions are repeated to ensure the derived endurance time is reproducible and accurate, and to determine error limits.

Because the AWS is sloped like an aircraft wing, the fluid flows down the AWS, mimicking the target test conditions more closely. With the addition of snow to the fluid, the upper portion of the AWS thins out sooner than the lower portion (primarily because of gravity pulling the fluid down the sloped plate), leaving a thinner layer of fluid at the top of the AWS than at its bottom. This also means the fluid failure usually begins at the top and continues down the AWS. In some instances, under heavier snowfall conditions, the snow can 
accumulate on the fluid quicker than it can be absorbed. In those instances, the entire surface of the AWS may fail at nearly the same time.

\section{b. AWS temperature relationship to fluid endurance times}

The snow machine allows for a systematic and repeatable examination of the performance of types II, III, and IV anti-icing fluids under snowfall conditions. Because the snow landing on the fluid dissolves into the fluid (even at temperatures below freezing), heat is exchanged between the fluid/AWS and the snow. Heat exchange between the snow and the fluid/AWS results in heat transferring from the fluid/AWS to the snow in an endothermic process that dissolves the snow into the fluid. This causes the AWS temperature to decrease rapidly at a rate proportional to the snowfall accumulating on (and being dissolved into) the fluid. As mentioned previously, a temperature probe was embedded into the underside of the AWS, centered approximately one-third of the way down the plate, which coincides with the typical failure point of the fluid on the AWS (where snow covers one-third of the plate and is no longer absorbed into the fluid). Figure 7 shows the condition of the test plate and ambient snow-machine temperature for a test with a fixed LWE snowfall rate of $40 \mathrm{~g} \mathrm{dm}^{-2} \mathrm{~h}^{-1}\left(4 \mathrm{~mm} \mathrm{~h}^{-1}\right)$. The AWS temperature at the beginning of the test was slightly below ambient temperature (because the fluid was slightly colder than ambient temperature when it was applied), but as the fluid dissolves the snow, the temperature of the AWS quickly drops $>5^{\circ} \mathrm{C}$ over the first $12 \mathrm{~min}$. At that point, the endothermic exchange of heat between the snow and the AWS/fluid slowed for a couple of minutes as the rate of snow dissolution into the fluid also slowed. After approximately $13 \mathrm{~min}$, the heat exchange ended, as the fluid no longer absorbed the snow. Thus, the AWS temperature began to rise because the ambient air temperature around the plate was warmer than the plate and thus the plate temperature began warming back to the ambient air temperature. The time at which the AWS temperature began to rise was usually coincident (within $5 \mathrm{~min}$ ) with the time that the observer visually determines that fluid failure has occurred. This association between fluid failure time and AWS temperature was consistent for all fluids. Under constant rate conditions, this pattern was highly reproducible using the snow machine, regardless of fluid type. Multiple fluid tests under various constant LWE snowfall rates consistently showed that the speed at which the temperature of the AWS decreases is proportional to the LWE snowfall rate. The higher the LWE snowfall rate (and thus the faster the snowfall mass increases), the quicker

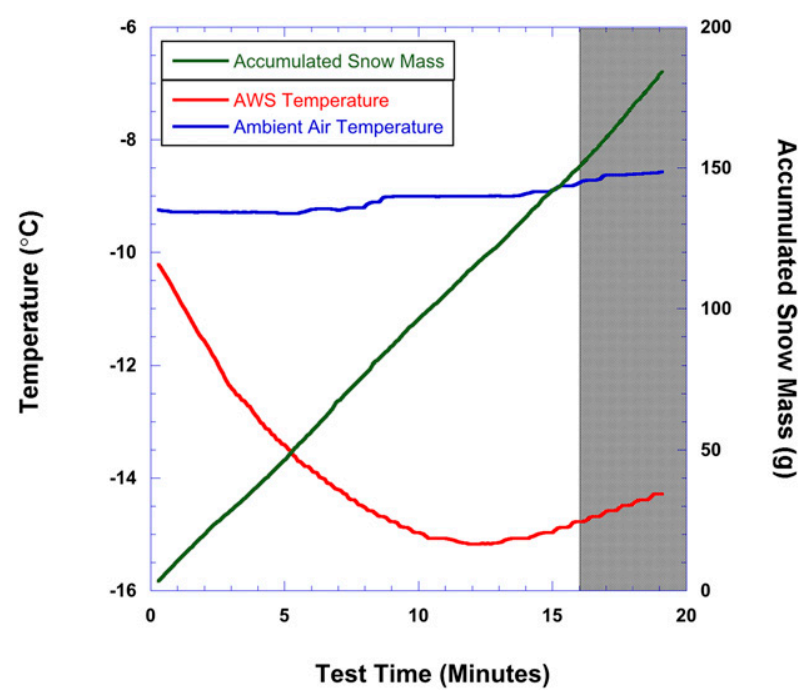

FIG. 7. Example fluid test using the snow machine showing the relationship of AWS temperature to fluid failure time. The gray shaded area is the period after which the fluid failure occurred.

the temperature of the AWS decreases and the quicker the fluid failure occurs.

This can be expressed by

$$
d R / d t=\left(R_{s} \Delta H \Delta H_{\text {solv }}\right) /\left(C \rho_{f} t\right),
$$

where $R_{s}$ is the LWE snowfall rate in $\mathrm{g} \mathrm{dm}^{-2} \mathrm{~h}^{-1}, \Delta H$ is the heat of enthalpy, $\Delta H_{\text {solv }}$ is the heat of solvation, $C$ is the heat capacity (assumed to be $0.96 \mathrm{cal} \mathrm{g}^{-1} \mathrm{~K}^{-1}$ as per the manufacturer), $\rho_{f}$ is the density of the anti-icing fluid (assumed to be $1.06 \mathrm{~g} \mathrm{~cm}^{-3}$ as per the manufacturer), and $t$ is the initial fluid thickness $(3 \mathrm{~mm})$ measured on the AWS. It is also assumed that the cooling by melting is equally distributed between the fluid and the aluminum plate. Because the anti-icing fluid mixture is a nearly equal combination of water and propylene glycol, it is assumed that the contribution of heat from the $\Delta H_{\text {solv }}$ term is small. Furthermore, since the $\Delta H$ term is the primary term responsible for dissolving the snow into the fluid, it is assumed its effects are similar to the latent heat of melting. Thus, Eq. (1) can be rewritten substituting the latent heat of melting in place of the heat of enthalpy and solvation,

$$
d R / d t=\left(R_{s} L_{m}\right) /\left(C \rho_{f} t\right),
$$

where $L_{m}$ is the latent heat of melting $\left(65 \mathrm{calg}^{-1}\right.$ at $-10^{\circ} \mathrm{C}$; Pruppacher and Klett 1997). The only dependence on fluid type is the heat capacity and density of the fluid, and thus all fluids should show similar behavior and should cool at the rate according to Eq. (2).

Calculating the rate of cooling at an ambient air temperature of $-10^{\circ} \mathrm{C}$ and an LWE snowfall rate of 


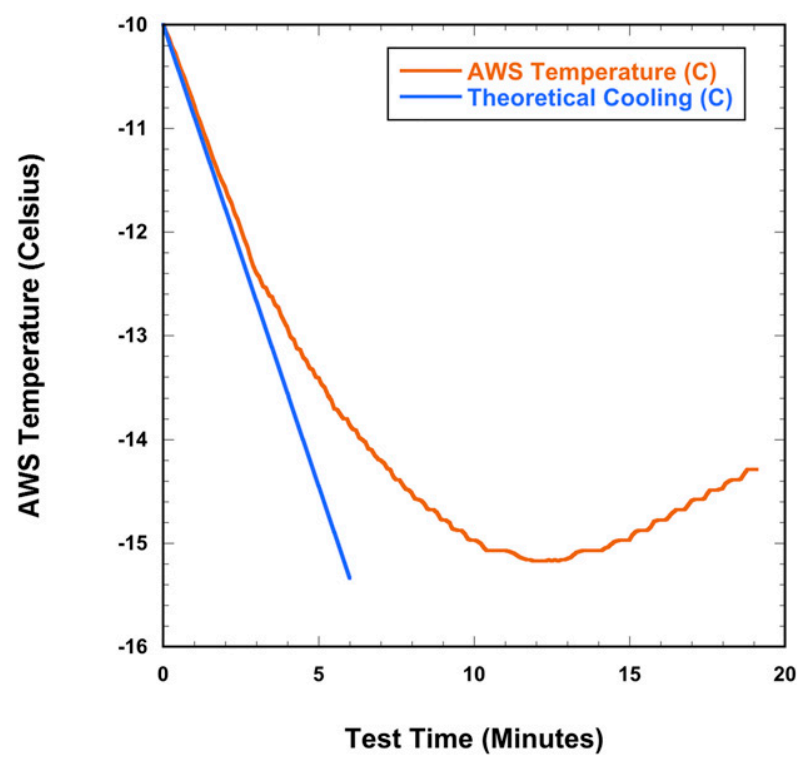

FIG. 8. Theoretical and observed cooling of the AWS at an ambient air temperature of $-10^{\circ} \mathrm{C}$ and an LWE snowfall rate of $25 \mathrm{~g} \mathrm{dm}^{-2} \mathrm{~h}^{-1}$. Note that the AWS temperature matched the air temperature at the start of the test.

$25 \mathrm{~g} \mathrm{dm}^{-2} \mathrm{~h}^{-1}$ produces a cooling rate of $0.89^{\circ} \mathrm{Cmin}^{-1}$. Thus, in $5 \mathrm{~min}$, the fluid would have cooled by $4.5^{\circ} \mathrm{C}$ (Fig. 8). Note that the initial cooling predicted by the theoretical curve agrees very well with the measured rate of cooling from an actual test in the snow machine. As time progresses, however, the observed cooling rate is slower than theoretically predicted. This is due to the slower rate at which snow dissolves when the fluid becomes increasing diluted with meltwater, resulting in a slower rate of temperature decrease. The fluid will also begin to thin with time because of the increased water content and from slowly moving down the plate under the influence of gravity. The rate of temperature drop also decreases because of the heat transfer from the ambient room air to the plate competing with the cooling from the snow melting. This heat transfer rate will be minimal at the start of the snowfall because of the air and plate temperatures being nearly the same but will increase rapidly as the AWS temperature decreases. The higher the LWE snowfall rate, the quicker the AWS temperature will drop. The good agreement between the initial observed plate cooling rate and the theoretical prediction confirms that the observed plate cooling is strongly controlled by the latent heat of melting of snow. Understanding this cooling process is key to understanding why the fluids stop absorbing snow (and thus stop providing protection to the airfoil). By using Eq. (2), it may be possible to model the failure of a given fluid by changing the appropriate variables over time to

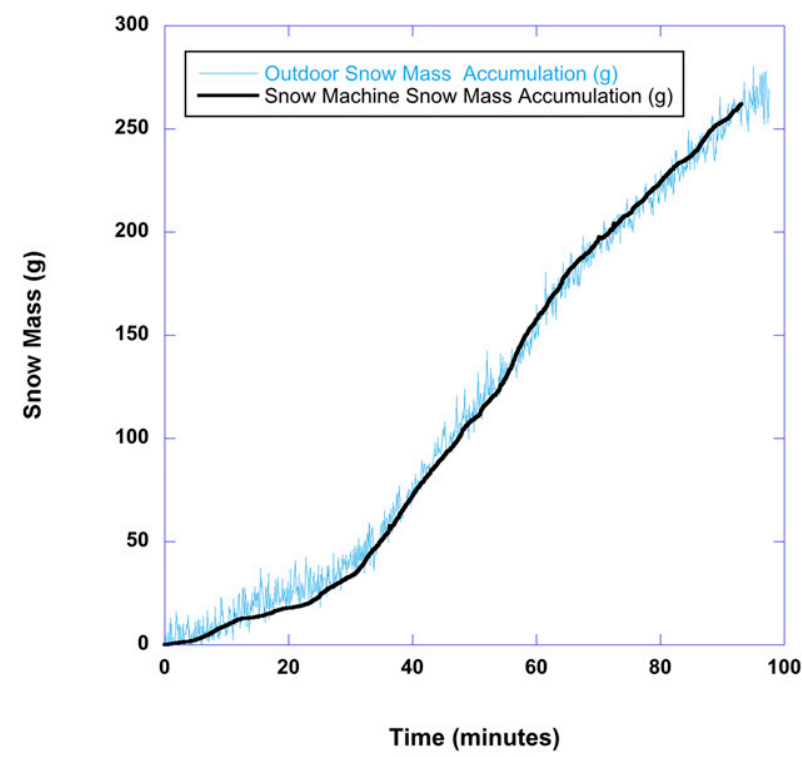

FIG. 9. Snow-machine simulation of outdoor-measured snow mass over time. The light blue line is the outdoor-accumulated snow mass and the black line is the snow-machine-accumulated snow mass.

give estimates of fluid failures that can be compared against actual tests.

\section{c. Comparison of indoor experiments with outdoor experiments}

To compare the outdoor tests with the indoor tests, outdoor measurements of accumulated mass were taken using the AWS, fluid containment assembly, and mass balance. These outdoor mass readings were then assimilated by the snow-machine software and converted to 6-s rates that could be reproduced in the machine. Additionally, measurements of initial fluid temperature and ambient air temperature were also taken during the outdoor experiments and recreated in the cold chamber as part of the indoor tests. The snow machine replicated the outdoor LWE snowfall rates very closely, although the outdoor snowfall mass rates were considerably more variable. The highly varying rates were likely due to wind impacting the AWS/fluid catchment assembly on the electronic balance (Fig. 9); the indoor snow mass was smoother because there was little to no wind in the snow machine.

Additional comparison tests between the snow machine and outdoor experiments were conducted using different types and concentrations of anti-icing fluids. A comparison of the outdoor fluid endurance times and associated snow-machine fluid endurance times (Fig. 10) shows that the snow-machine tests are highly correlated to the outdoor tests with a correlation coefficient of 0.96. However, a nearly 14-min bias appears to exist 


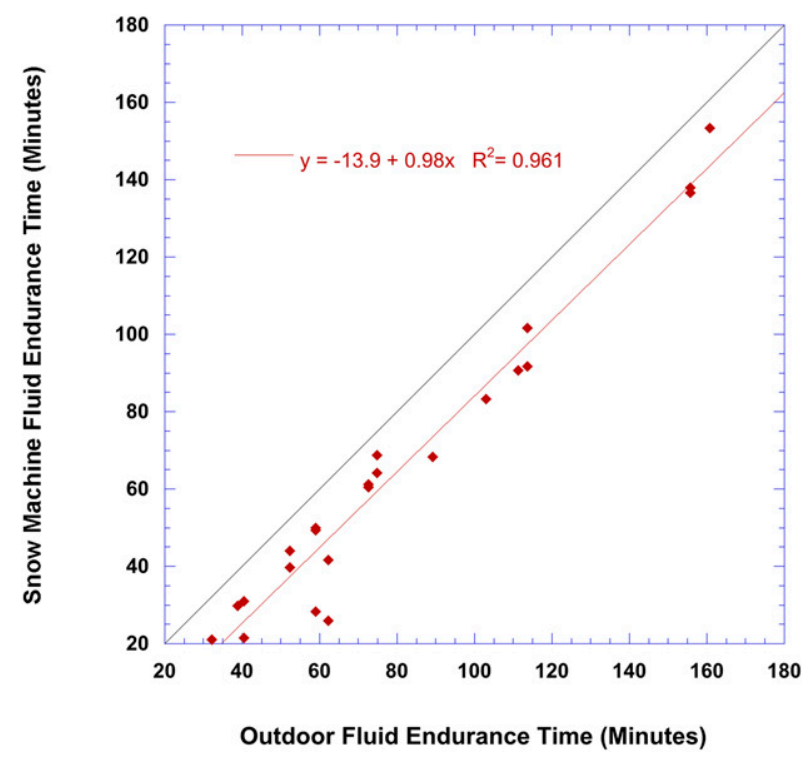

FIG. 10. Comparison of snow-machine endurance times with outdoor endurance times.

independent of the overall endurance times, as the indoor snow-machine endurance times are always shorter than the outdoor endurance times.

AWS temperature measurements were compared between the outdoor testing and the indoor laboratory snowmachine tests for a type IV fluid (Fig. 11). Both plate temperatures began near $-4^{\circ} \mathrm{C}$ (which was also the ambient outdoor temperature throughout the experiment) and both AWS temperatures dropped several degrees below the ambient temperature at the beginning of the experiment. However, the AWS temperature in the snow machine decreased more than the AWS temperature from the outdoor test. It is hypothesized that wind was counteracting the cooling effect of the plate and fluid for the outdoor experiment by increasing the heat transfer from the ambient air to the AWS and thus keeping the fluid and AWS slightly warmer. Because the snow-machine testing is done in a nearly calm wind environment, the plate temperature decreased more than the outdoors, resulting in an earlier failure of the fluid. Using the linear regression equation calculated for the data shown in Fig. 12, a bias correction can be applied to the snow-machine data to correct the failure and endurance times to match the variables most likely expected for an outdoor experiment. Research is ongoing to better determine the cause(s) for the shorter endurance times in the snow machine.

\section{d. Endurance time determination}

While SAE (2008) establishes the methodology for determining when anti-icing fluids fail under a given ambient air temperature and LWE snowfall rate, it is not

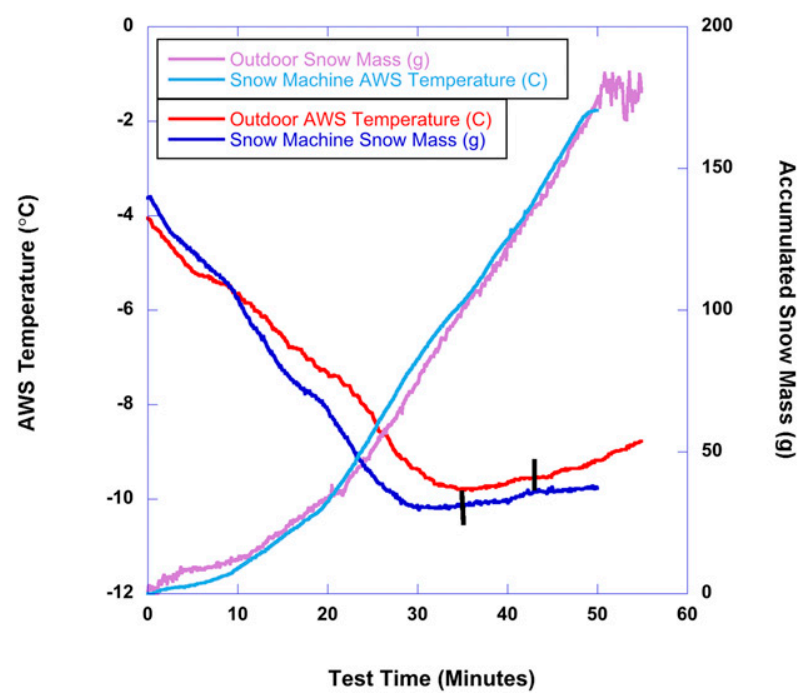

FIG. 11. Example of an outdoor anti-icing fluid test as compared with a similar indoor snow-machine test. The vertical black bars on the temperature traces indicate the approximate endurance time of the fluid.

practical to test every combination of ambient air temperature and LWE snowfall rate an aircraft may encounter. Once the tests have been completed for a variety of conditions (typically three to four rates and four to five temperatures), the endurance times can be plotted as a function of LWE snowfall rate. The relationship between LWE snowfall rates and fluid endurance times is similar for five different type IV fluids (Fig. 12), and can be described by an inverse power law. A power-law curve is fit to the data as in Eq. (3), where ET is the endurance time in minutes, $S$ is the LWE snowfall rate in $\mathrm{g} \mathrm{dm}^{-2} \mathrm{~h}^{-1}$ and $a$ and $b$ are constants of the curve fit to the data,

$$
\mathrm{ET}=a S^{b} .
$$

This relationship has been shown to be robust for every anti-icing fluid tested to date. Once the power-law curve fit is established, a pilot or deicing ground crew will need to know only the type of anti-icing fluid, the ambient air temperature, and the LWE snowfall rate to know how long the anti-icing fluid will protect the aircraft. This information is typically published by the FAA in tabular form and is referred to as the holdover time guidelines, which are updated yearly as new fluids are characterized.

\section{Summary of results}

The National Center for Atmospheric Research (NCAR) has developed an artificial snow-generation system "snow machine" to use in a laboratory cold-chamber environment. It has been demonstrated that the snow 


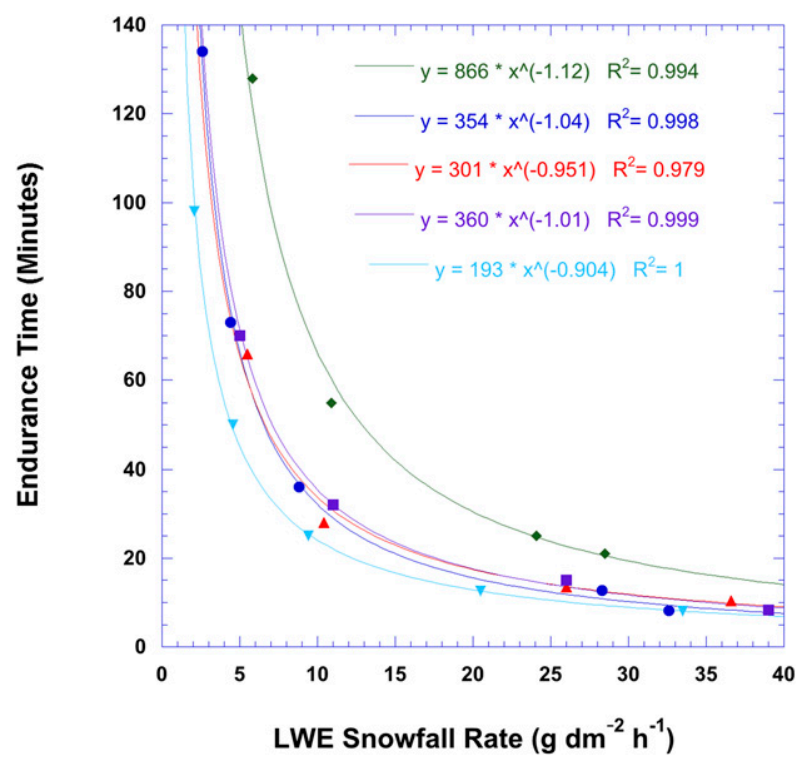

FIG. 12. Endurance time as a function of LWE snowfall rates for five different type IV anti-icing fluids. Each color represents a different fluid.

machine can accurately replicate natural snowfall conditions through comparisons between outdoor rates versus machine-generated rates. When used for determining anti-icing fluid endurance times, a comparison with data from outdoor tests revealed that the snow machine exhibited a consistent bias (approximately 15\%) toward shorter endurance times. The measured test plate temperatures of the outdoor experiments showed that the plate fluid temperatures remained higher when similar testing was performed with the snow machine. It is hypothesized that this may be due to wind partially counteracting the cooling of the AWS/fluid due to heat being transferred to the snowmelt from the warmer air blowing across it as it is being absorbed into the fluid.

A major finding from using the snow machine was the significant cooling effect, up to $8^{\circ} \mathrm{C}$, of the plate induced by snow melting into the anti-icing fluid under calm wind conditions and high LWE snowfall rate. This factor was not considered in prior studies of anti-icing fluids and represents a major influence on the endurance time of the fluids, especially under light wind conditions.

Overall, the snow machine has proven to be a robust tool for controlled snow generation in a laboratory environment, mimicking natural snowfall at reproducible rates. As an application, it provides a reliable means of testing the anti-icing fluids used to prevent snow accumulation on aircraft wings on the ground before takeoff.

Additional testing and development of the snow machine is ongoing, with the goals of determining the effect of wind on the fluid endurance times and further testing of the machine at colder temperatures (to $-30^{\circ} \mathrm{C}$ ) and higher LWE snowfall rates $\left(>50 \mathrm{~g} \mathrm{dm}^{-2} \mathrm{~h}^{-1}\right)$. Outdoor tests of the fluids utilizing an AWS in a double-fence intercomparison reference (DFIR) shield (Rasmussen et al. 2012) to minimize the wind versus an unshielded AWS are also planned to further study the impacts of wind under natural snowfall conditions.

Acknowledgments. This research is in response to requirements of and funding by the Federal Aviation Administration (FAA; Award DTFAWA-15-D-00036). The views expressed are those of the authors and do not necessarily represent the official policy or position of the FAA. The National Center for Atmospheric Research is sponsored by the National Science Foundation. The authors acknowledge the support of Charlie Masters, James Riley, and Timothy Smith of the FAA. We also acknowledge the support of APS Aviation Inc. for its feedback on the artificial snow-generation system, NCAR Design and Fabrication Services for its assistance in manufacturing various components of the machine, and Karen Slater of NCAR for her editing efforts.

\section{REFERENCES}

Beisswenger, A., K. Bouchard, and J. L. LaForte, 2002: Development of a procedure for indoor testing of type IV fluids to replicate natural snow. FAA Rep. DOT/FAA/AR-02/82, 46 pp.

Bernadin, S., C. Dubuisson, and J. L. Laforte, 1997: Development of laboratory test procedures to replace field anti-icing fluid tests: Snow equivalence tests. Université du Québec à Chicoutimi Anti-icing Materials International Laboratory (AMIL) Publ., 136 pp.

Pruppacher, H. R., and J. D. Klett, 1997: Microphysics of Clouds and Precipitation. 2nd ed. Kluwer Academic Publishers, 954 pp.

Rasmussen, R. M., A. J. Hills, S. D. Landolt, and C. A. Knight, 1999a: Results of holdover time testing of type IV anti-icing fluids with the improved NCAR artificial snow generation system. FAA Rep. DOT/FAA/AR-99/10, 36 pp.

_ C. A. Knight, and A. J. Hills, 1999b: Development of a method to test holdover times of deicing and anti-icing fluids in a cold room using artificially generated snow. FAA Rep. DOT/FAA/AR-98/74, 21 pp.

— S. Landolt, M. Tryhane, and A. Hills, 2003: Endurance time testing using the NCAR snow machine: Reconciliation of outdoor and indoor tests of type IV fluids. FAA Rep. DOT/ FAA/AR-03/54, $36 \mathrm{pp}$.

_ M. Tryhane, S. Landolt, and A. Hills, 2006: Endurance time tests using the NCAR snow machine: Results of round-robin tests using a constant test plate temperature. FAA Rep. DOT/ FAA/AR-05/58, 42 pp.

— The NOAA/FAA/NCAR winter precipitation test bed. Bull. Amer. Meteor. Soc., 93, 811-829, https://doi.org/10.1175/BAMSD-11-00052.1.

SAE, 2008: Endurance time tests for aircraft deicing/anti-icing fluids SAE Type II, III, and IV. SAE International Aerospace Recommended Practice AR5485, 51 pp. 